\title{
Kajian Kebutuhan Alat Berat pada Pekerjaan Tanah Pembangunan Turap atau Pematangan Lahan Parkir Kecamatan Pelayangan Seberang Kota Jambi
}

\author{
Annisaa Dwiretnani ${ }^{1}$, Ilham Alfhito Putra ${ }^{2}$ \\ ${ }^{1}$ Dosen Fakultas Teknik Universitas Batanghari \\ ${ }^{2}$ Mahasiswa Fakultas Teknik Universitas Batanghari \\ Email : annisaa.dwiretnani@gmail.com
}

\begin{abstract}
Heavy equipment commonly used in construction projects are Dump trucks, excavators, dozers, soil compactors such as rollers and compactors. The purpose of using these heavy equipment is to make it easier for people to do the work so that the expected results can be achieved more easily in a relatively shorter time and as a reference to find out the needs of the equipment used in the work location whether or not they are needed (Aoliya, 2017). In the pavement / ripening development project Pelayangan sub-district parking lot across the city of Jambi the heavy equipment used is; excavators, dump trucks and dozers. The project which began in June 2017 was completed in December 2017. Based on observations of researchers in the field for the use of 2 (two) pieces of excavator used, 1 (one) dozer, and 20 (twenty) dump trucks. The use of heavy equipment used in the field is not yet known optimal productivity. An analysis of the calculation of the needs of heavy equipment is needed in the construction project of the pavement / ripening of the parking area of Pelayangan Seberang Subdistrict, Jambi City. This study consists of several stages, namely calculating the production capacity of each heavy equipment, calculating the value of productivity, then calculating the number of each tool needed, and in the final stage comparing the number of tools analyzed according to calculations with the number of tools in the field.
\end{abstract}

Keywords: Heavy Equipment, Heavy Equipment Needs, Heavy Equipment Productivity

\section{PENDAHULUAN}

Alat berat merupakan salah satu sumber daya peralatan yang digunakan dalam suatu proyek. Keuntungan menggunakan alat berat dibanding dengan alat manual yaitu dapat menyelesaikan pekerjaan pembangunan lebih cepat. Sehingga tidak perlu memakan waktu lama untuk bisa menyelesaikannya. Alat berat yang umum dipakai dalam proyek konstruksi adalah Dump truck, alat gali (excavator), dozer, alat pemadat tanah seperti roller dan compactor, dan lainlain (Pratasis, 2016).

Pada proyek pembangunan turap / pematangan lahan parkir kecamatan Pelayangan seberang kota Jambi alat berat yang digunakan yaitu; excavator, dump truck dan dozer. Proyek yang dimulai pada bulan Juni 2017 selesai pada Desember 2017. Berdasarkan pengamatan peneliti di lapangan untuk penggunaan alat berat excavator yang digunakan sebanyak 2 (dua) buah, dozer 1 (satu) buah, dan dump truck sebanyak 20 (dua puluh buah).

Penggunaan alat berat yang digunakan di lapangan belum diketahui produktivitas optimalnya. Dari permasalahan diatas maka diperlukan suatu analisa perhitungan kebutuhan alat berat pada proyek pekerjaan pembangunan turap / pematangan lahan parkir kecamatan pelayangan seberang kota jambi, yang dibutuhkan dan analisa waktu pelaksanaan yang dibutuhkan oleh masing - masing alat, dengan memperhatikan langkah - langkah perhitungan, yaitu : menghitung kapasitas produksi setiap alat berat agar diperoleh nilai produktifitasnya, sehingga jumlah masing - masing alat yang dibutuhkan dapat ditentuka, agar dapat mengetahuin jumlah alat yang dianalisa dan yang di lapangan apakah sesuai atau tidak. Adapun judul dari penelitian ini yaitu, pembangunan turap / pematangan lahan parkir kecamatan Pelayangan seberang kota Jambi.

\section{Landasan Teori Alat Berat}

Alat berat adalah alat yang sengaja diciptakan/didesain untuk dapat melaksanakan salah satu fungsi/ kegiatan proses kontruksi yang sifatnya berat bila dikerjakan oleh tenaga manusia, seperti : mengangkut, mengangkat, memuat, memindah, menggali, mencampur dan seterusnya dengan cara mudah, cepat, hemat dan aman (Asiyanto,2008).

Dalam bidang teknik sipil, alat-alat berat yang digunakan untuk membantu manusia dalam melakukan pekerjaan pembangunan suatu struktur bangunan. Tujuan penggunaan alat-alat berat adalah untuk memudahkan manusia dalam pengerjaan sehingga hasil yang diharapakan dapat tercapai dengan mudah pada waktu yang relative singkat. (Susy Fatena Rostiyanti,2008).

\section{Prinsip dasar perhitungan produksi kerja}

Sebagaimana telah dinyatakan sebelumnya bahwa Produksi alat berat di pengaruhi tiga faktor utama yaitu Waktu Siklus, Jenis material dan faktor efesiensi. Dari ketiga faktor tersebut, jenis material adalah faktor yang sangat menentukan.

\section{Perhitungan Kerja Alat Berat Terhadap Waktu}

Maksud dari "waktu" adalah waktu yang diperlukan untuk merampungkan satu siklus pekerjaan. Inilah yang disebut waktu siklus. Waktu siklus Alat Berat secara garis besar terdiri dari 2 bagian, yaitu:

1. Waktu tetap (Fixed Time)

2. Waktu tidak tetap (Variable Time)

\section{Menghitung Kapasitas Aktual}

Menghitung material yang terbawa dalam satu siklus kerja merupakan langkah pertama yang harus dilakukan. Kapsitas actual (muatan per siklus) ini tergantung pada ukuran mangkok pembawa material yang ada pada setiap alat Bucket Excavator dan jenis 
material yang diolah. Jadi untuk menentukan besarnya kapasitas actual ini perlu diketahui dahulu data tentang ukuran Bucket dari Alat Berat yang dioperasikan dan faktor muatan atau Carry Factor jenis material.

\section{Menghitung Waktu Siklus}

Waktu siklus dihitung untuk mendapatkan jumlah siklus per jam. Waktu siklus tersebut terdiri dari waktu tetap dan waktu variable. Waktu ini sering ditetapkan sebagai waktu konstan untuk semua jenis material dan kondisi. Tentunya penetapan waktu tetap dilakukan berdasarkan penelitian-penelitian yang telah dilakukan sebelum alat tersebut dipasarkan. Biasanya dalam lembaran spesifikasi diberikan data-data tentang waktu ini. Sedangkan waktu variable harus dihitung berdasarkan keadaan-keadaan sebenarnya dilapangan dengan mengamati setiap kondisi yang mungkin akan mempengaruhi produksi kerja Alat Berat.

\section{Produksi kerja satu unit peralatan Excavator}

Excavator adalah adalah alat yang serba guna yang dapat untuk menggali tanah, membuat parit, memuat material ke dump truck atau kayu ke trailer(Pratasis, 2016).

Empat langkah perhitungan yang perlu dilakukan dalam menghitung produksi kerja Excavator, yaitu:

1. Menghitung kapasitas Aktual Bucket

Menghitung isi aktual Bucket adalah menghitung volume material yang terangkut Bucket Excavator dalam satu siklus kerja. Isi aktual tergantung pada kapasitas Bucket dan jenis material. Kapasitas Bucket adalah daya muat berdasarkan akurat Bucket dan model alatnya. Sedangkan "Carry Factor" ditentukan berdasarkan jenis material yang diolah.

Kapasitas Aktual Bucket $=$ Kapasitas Bucket $\times$ Carry Factor

2. Menghitung Waktu Siklus

Waktu siklus Excavator dipengaruhi oleh beberapa faktor seperti mudah atau sukarnya material dimuat atau digali, kedalaman galian, ketinggian timbunan tanah galian dan sudut ayun. Siklus kerja Excavator terdiri dari empat gerakan yakni:
a. Memuat Bucket
b. Mengayun bermuatan
c. Dumping (Pembuangan)
d. Mengayun kosong

$$
\text { Jumlah Siklus / Jam }=\frac{60 \text { menit }}{\text { Total Waktu Siklus }}
$$

3. Menghitung Produksi Kerja Kasar

Produksi kerja kasar adalah jumlah material yang sanggup digali Excavator dalam satu jam tanpa memperhitungkan faktor-faktor efisiensi.

Produksi Kerja Kasar = Kapasitas Aktual Bucket $\mathrm{x}$ Jumlah Siklus Per Jam

4. Menghitung Produksi Kerja Aktual Produksi kerja aktual adalah hasil produksi kasar dikalikan dengan faktor efisiensi kerja.
Produksi Kerja Aktual $=$ Kapasitas Kerja Kasar $\mathrm{x}$ Faktor Efisiensi Kerja

\section{Dump Truck}

Dump truck adalah truk yang isinya dapat dikosongkan tanpa penanganan. Dump truk biasa digunakan untuk mengangkut barang semacam pasir, kerikil atau tanah untuk keperluan konstruksi ( Pratasis, 2016 ). Analisis produksi kerja Dump Truck adalah menghitung kemampuan alat mengangkut material dalam satu jam kerja. Untuk Dump Truck ini perhitungannya mengikuti empat langkah perhitungan, yaitu :

1. Menghitung Kapasitas Aktual Bak

Kapasitas aktual bak tergantung pada ukuran bak dan faktor muatan.

Kapasitas Muat Aktual = Kapasitas Bak x Faktor Muat

2. Menghitung Waktu Siklus.

Waktu Siklus Dump Truck terdiri dari :
a. Waktu muat
b. Waktu monuver di tempat permuatan
c. Waktu angkut
d. Waktu kembali

Produksi Kerja Kasar $=$ Kapasitas Muat Aktual $\times$ Jumlah Siklus/jam

\section{Menghitung Produksi Kerja Aktual}

Produksi Kerja Aktual $=$ Produksi Kerja Kasar $\times$ Faktor Efisiensi

\section{HASIL DAN PEMBAHASAN Spesifikasi Alat Berat \\ Excavator.}

Adapun fungsi Excavator secara umum adalah untuk Excavating (menggali), Loading (memuat material), Lifting (mengangkat beban), Hammering (menghancurkan batuan).

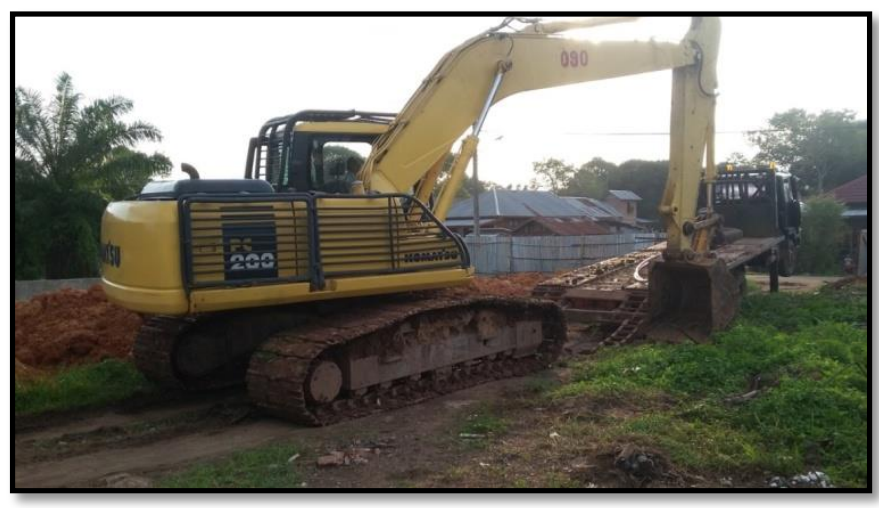

Gambar 1 Excavator

Sumber: Foto Observasi Lapangan (2018)

$\begin{array}{ll}\text { Spesifikasi } & \\ \text { Merek } & : \text { KOMATSU } \\ \text { Kondisi } & : 80 \% \text { (Baik) } \\ \text { Berat Operasi } & : 20 \text { ton } \\ \text { Ketinggian pemutar maksimum } & : 5840 \mathrm{~mm} \\ \text { Kedalaman penggalian maksimum } & : 6095 \mathrm{~mm}\end{array}$


Faktor Bucket

Kapasitas Bucket

\section{Dozer.}

Dozer adalah Alat untuk meratakan ataupun memotong tanah pada pekerjaan timbunan agar bisa mendapatkan elevasi sesuai dengan yang di inginkan, berfungsi juga untuk mendorong tanah dan batuan di lokasi pekerjaan.

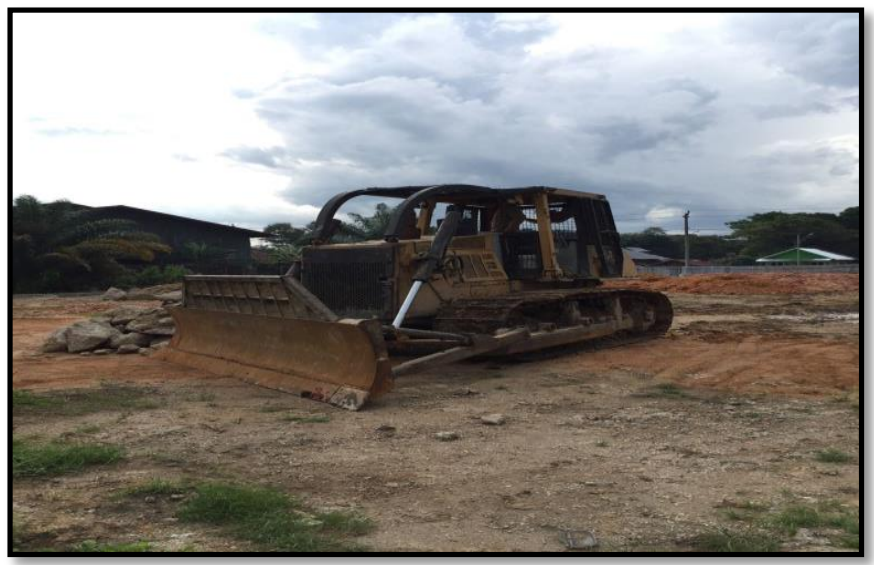

Gambar 2 Dozer

\section{Spesifikasi}

Sumber: Foto Observasi Lapangan (2018)

Merk

Kondisi

Tenaga roda max

Bobot oprasi

Kapasitas bahan bakar full

Transmisi maju max

Transmisi mundur max

Panjang dozer

Tinggi dozer

Lebar dozer

Kapasitas pisau

Berat pisau

Max menggali kedalaman

$$
\begin{aligned}
& =\text { Cat } 3306 \mathrm{~T} \\
& =75 \% \\
& =131 \mathrm{~mm} \\
& =16880 \mathrm{~kg} \\
& =320 \mathrm{~L} \\
& =10,8 \mathrm{~kg} / \mathrm{jam} \\
& =12,9 \mathrm{~kg} / \mathrm{jam} \\
& =3937 \mathrm{~mm} \\
& =3057 \mathrm{~mm} \\
& =2440 \mathrm{~mm} \\
& =3,27 \mathrm{~m}^{3} \\
& =1309 \mathrm{~kg} \\
& =6095 \mathrm{~mm}
\end{aligned}
$$

\section{Dump Truck.}

Dump Truck adalah alat berat yang sangat sering digunakan dalam berbagai kegiatan proyek, penggunaan alat ini sangat dominan dan berfungsi sebagai alat pengangkut material dan lain sebagainya.

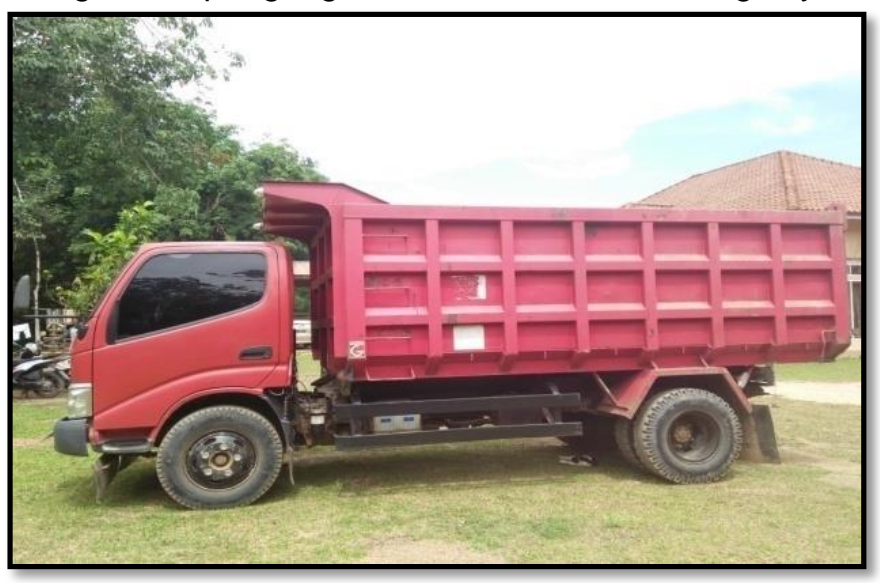

Gambar 3 Dump Truck

Sumber: Foto Observasi Lapangan (2018)
Kecepatan angkut : $25 \mathrm{~km} / \mathrm{jam}$ Kecepatan kembali : $50 \mathrm{~km} / \mathrm{jam}$ Faktor efisensi : 0,75

\section{Pekerjaan yang Dianalisa.}

Jenis pekerjaan yang akan dianalisa untuk memperoleh produktivitas alat berat yaitu sebagai berikut :

1. Pekerjaan galian dan urugan tanah menggunakan alat berat seperti excavator.

2. Pekerjaan perataan tanah dan pemotongan elevasi di gunakan alat dozer.

3. Pekerjaan penimbunan dan pengangkatan matrial menggunakan dam truck.

\section{Perhitungan Analisa Alat Berat. \\ Excavator}

Dalam proyek ini digunakan Excavator dengan kondisi kerja sebagai berikut:
Kapasitas Bucket
$: 0,442 \mathrm{~m}^{3}$
Efisiensi kerja
$: 0,75$
Carry faktor
: 0,9 (Pasir dan Kerikil)

Produksi kerja Excavator per jam, yaitu:

- Kapasitas aktual Bucket = Kapasitas Bucket $\times$ Carry Factor $=0,442 \times 0,9$

$$
=0,40 \mathrm{~m}^{3}
$$

- Waktu Siklus :

Mengisi Bucket $\quad=6$ detik (Rata-rata $0 \mathrm{~m}-2 \mathrm{~m}$ )

Mengayun bermuatan $=5$ detik $\left(45^{\circ}-90^{\circ}\right)$

Dumping (pembuangan) $=3$ detik

Mengayun kosong $\quad=4$ detik

Total waktu siklus $\quad=18$ detik

- Jumlah Siklus/Jam

\section{0 menit}

\section{$=\overline{\text { Total Waktu Siklus }}$}

$$
\begin{aligned}
& =\frac{60 \times 60 \text { detik }}{18 \text { detik }} \\
& =200 \text { siklus/jam }
\end{aligned}
$$

- Produksi kerja kasar

= Kapasitas aktual Bucket $\mathrm{x}$ jumlah siklus/jam

$$
=0,40 \times 200
$$$$
=80 \mathrm{~m}^{3} / \mathrm{jam}
$$

- Produksi kerja aktual

$=$ Produksi kerja kasar $\mathrm{x}$ Faktor efisiens kerja

$$
\begin{aligned}
& =80 \times 0,75 \\
& =60,00 \mathrm{~m}^{3} / \mathrm{jam}
\end{aligned}
$$

Tabel 1. Rekapitulasi Analisis Excavator

\begin{tabular}{clc}
\hline NO & \multicolumn{1}{c}{ ANALISIS } & HASIL PERHITUNGAN \\
\hline 1 & Kapasitas Aktual & $0,40 \mathrm{~m}^{3}$ \\
2 & Waktu Siklus & 18 detik \\
3 & Jumlah Siklus & 200 siklus/jam \\
4 & Produksi Kerja Siklus & $80 \mathrm{~m}^{3} / \mathrm{jam}$ \\
5 & Produksi Kerja Aktual & $60 \mathrm{~m}^{3} / \mathrm{jam}$
\end{tabular}

Sumber: (Hasil Perhitungan, 2018)

\section{Dump Truck.}

Analisis produksi kerja Dump Truck adalah menghitung kemampuan alat mengangkut material dalam satu jam kerja. Dalam proyek jalan ini dioperasikan Dump Truck untuk mengangkut material dari lokasi quarry ke lapangan dengan kondisi kerja sebagai berikut:

$\begin{array}{ll}\text { Kapasitas bak } & : 5,7 \mathrm{~m}^{3} \\ \text { Waktu muat } & : 1,40 \text { menit }\end{array}$




$\begin{array}{ll}\text { Waktu buang } & : 1,00 \text { menit } \\ \text { Waktu tetap } & : 0,80 \text { menit } \\ \text { Kecepatan angkut } & : 25 \mathrm{~km} / \mathrm{jam} \\ \text { Kecepatan kembali } & : 50 \mathrm{~km} / \mathrm{jam} \\ \text { Jarak angkut/kembali } & : 40 \mathrm{~km} \\ \text { Faktor isi } & : 0,9 \\ \text { Faktor efisensi kerja } & : 0,75\end{array}$

- Kapasitas muat aktual $=$ Kapasitas bak $\times$ faktor isi $=57 \times 0,9$

$=51,3 \mathrm{~m}^{3}$

- Waktu Siklus Waktu muat

Waktu buang

Waktu angkut

Waktu kembali

Waktu tetap

Total Waktu Siklus

$=1,40$ menit

$=1,00$ menit

$=\underline{40000 \times 60 \text { menit/jam }}=96$ menit

$25000 \mathrm{~m} / \mathrm{jam}$

$=\underline{40000 \times 60 \text { menit/jam }}=48$ menit

$50000 \mathrm{~m} / \mathrm{jam}$

$=0,80$ menit

- Produksi kerja kasar siklus/jam

$=147,20$ menit

menit)]

$=$ Kapasitas muat aktual $\mathrm{x}$ jumlah

$=51,3 \mathrm{~m}^{3} \times[(60$ menit/jam $) /(147,20$

$=20,91 \mathrm{~m}^{3} / \mathrm{jam}$

- Produksi kerja aktual

$=$ Produksi kerja kasar $\mathrm{x}$ Faktor efisiensi $=20,91 \times 0,75$

$=15,68 \mathrm{~m}^{3} / \mathrm{jam}$

Tabel 2. Rekapitulasi Analisis Dump Truck

\begin{tabular}{clc}
\hline NO & \multicolumn{1}{c}{ ANALISIS } & HASIL PERHITUNGAN \\
\hline 1 & Kapasitas Muat Aktual & $51,3 \mathrm{~m}^{3}$ \\
2 & Waktu Siklus & $147,20 \mathrm{menit}^{3}$ \\
3 & Produksi Kerja Kasar & $20,91 \mathrm{~m}^{3} / \mathrm{jam}$ \\
4 & Produksi Kerja Aktual & $15,68 \mathrm{~m}^{3} / \mathrm{jam}$ \\
\hline
\end{tabular}

Sumber: (Hasil Perhitungan, 2018)

\section{Dozer}

Untuk membentuk permukaan jalan dioperasiakan dozer dengan data kondisi kerja sebagai berikut:

$\begin{array}{ll}\text { Lebar sudu blade } & =3,21 \mathrm{~m} \\ \text { Tinggi sudu blade } & =1,127 \mathrm{~m} \\ \text { Faktor sudu } & =0,80 \\ \text { Jarak gusur } & =100 \mathrm{~m} \\ \text { Kecepatan } & =0-3,7 \mathrm{~km} / \mathrm{jam} \\ \text { maju } & =0-8,2 \mathrm{~km} / \mathrm{jam} \\ \text { mundur } & =0,75\end{array}$

- Waktu Siklus

1. Produksi per siklus

$\mathrm{q} \quad=$ Tinggi sudu $X$ lebar sudu $X$ faktor sudu

$=1,127^{2} \times 3,21 \times 0,80$

$=3,261 \mathrm{~m}^{2}$

2. Kec. Majuf $=3,7 \times 0,75=2,77 \mathrm{~km} / \mathrm{jam}(46,1 \mathrm{~m} / \mathrm{min})$

3. Kec. Mundur $=8,2 \times 0,85=6,97 \mathrm{~km} / \mathrm{jam}(116,1 \mathrm{~m} / \mathrm{min})$

4. Waktu ganti persnelling $z=0,05$

5. Waktu siklus $=\frac{100}{46,1}+\frac{100}{116,1}+0,05=3,08$ menit

6. Efesiensi kerja $=0,75$

- Produktifitas sesungguhnya, faktor konversi volume tanah.

Lepas $f=1,00$

Asli $f=0,80$

- Produktifitas untuk tanah lepas

$\mathrm{Q}=\frac{3,261 \times 60 \times 0,75 \times 1,00}{3,08}=47,64 \mathrm{~m}^{3} / \mathrm{jam}$

- Produttifitas untuk tanah asli

$\mathrm{Q}=\frac{3,261 \times 60 \times 0,75 \times 0,80}{3,08}=38,11 \mathrm{~m}^{3} / \mathrm{jam}$

Total siklus

$=85,75 \mathrm{~m}^{3} / \mathrm{jam}$

- Produksi kerja kasar Per jam

$=$ Luas Lintasan Kerja $\mathrm{x}$ Jumlah Siklus

$=100 \times(60$ menit/jam / 85,75 menit $)$

$=69,97 \mathrm{~m}^{2} / \mathrm{jam}$

- Produksi kerja aktual

$=$ Produksi kerja kasar $\mathrm{x}$ Faktor efisiensi
$=69,97 \times 0,75$

$=52,47 \mathrm{~m}^{2} / \mathrm{jam}$

Tabel 3. Rekapitulasi Analisis Dozer

\begin{tabular}{clc}
\hline NO & \multicolumn{1}{c}{ ANALISIS } & HASIL PERHITUNGAN \\
\hline 1 & Waktu siklus & $85,75 \mathrm{menit}$ \\
2 & Produksi Kerja Kasar & $69,97 \mathrm{~m}^{2} / \mathrm{jam}$ \\
3 & Produksi Kerja Aktual & $52,47 \mathrm{~m}^{2} / \mathrm{jam}$ \\
\hline
\end{tabular}

Sumber: (Hasil Perhitungan, 2018)

\section{Produksi Kerja Alat Berat.}

Berdasarkan hasil analisa perhitungan diatas maka diperoleh produksi kerja masing-masing alat berat, yaitu:

\section{Excavator.}

Material agregat

Produksi kerja per jam

Waktu kerja per hari

Jumlah hari kerja

$$
\begin{aligned}
& =1474,5 \mathrm{~m}^{3} \\
& =60,00 \mathrm{~m}^{3} / \mathrm{jam} \\
& =8 \mathrm{jam} \\
& =\frac{\text { Material agregat }}{\text { Produksi kerja } \times \text { waktu kerja }} \\
& =\frac{1474,5}{60,00 \times 8} \\
& =3,07 \text { hari }
\end{aligned}
$$

\section{Dump Truck.}

Material agregat

Produksi kerja per jam

Waktu kerja per hari

Jumlah hari kerja

\section{Dozer}

Material agregat

Produksi kerja per jam

Waktu kerja per hari

Jumlah hari kerja

$$
\begin{aligned}
& =1474,5 \mathrm{~m}^{3} \\
& =15,68 \mathrm{~m}^{3} / \text { jam } \\
& =8 \text { jam } \\
& =\frac{\text { Material agregat }}{\text { Produksi kerja } \times \text { waktu kerja }} \\
& =\frac{1474,5}{15,68 \times 8} \\
& =\text { hari } 11,75 \text { hari } \\
& =1474,5 \mathrm{~m}^{3} \\
& =52,47 \mathrm{~m}^{2} / \text { jam } \\
& =8 \text { jam } \\
& =\frac{\text { material agregat }}{\text { Produksi kerja } \times \text { waktu kerja }} \\
& =\frac{1474,5}{52,47 \times 8} \\
& =3,51 \text { hari }
\end{aligned}
$$

\section{Perhitungan kebutuhan alat berat}

Excavator

$$
=\frac{60,00 \mathrm{~m}^{3} / \mathrm{jam}}{60,00 \mathrm{~m}^{3} / \mathrm{jam}}=1 \text { Unit. }
$$

Dump truck

$$
=\frac{60,00 \mathrm{~m}^{3} / \mathrm{jam}}{15,68 \mathrm{~m}^{3} / \mathrm{jam}}=3,8=4 \text { Unit. }
$$

Dozer

$$
=\frac{60,00 \mathrm{~m}^{3} / \mathrm{jam}}{52,47 \mathrm{~m}^{3} / \mathrm{jam}}=1,15=1 \text { Unit. }
$$

Tabel 4. Rekapitulasi Perbandingan Jumlah Hari Kerja Alat Berat

\begin{tabular}{clcc}
\hline NO & Jenis Alat Berat & Perhitungan (Hari) & Realisasi (Hari) \\
\hline 1 & Excavator & 3,07 & 14 \\
2 & Dozer & 3,51 & 12 \\
3 & Dump Truck & 11,75 & 21 \\
\hline
\end{tabular}

(Hasil Perhitungan, 2018) kerja 
Tabel 5. Rekapitulasi Perbandingan Kebutuhan Alat Berat

\begin{tabular}{clcc}
\hline NO & Jenis Alat Berat & $\begin{array}{c}\text { Perhitungan } \\
\text { (Unit) }\end{array}$ & Realisasi (Unit) \\
\hline 1 & Excavator & 1 & 1 \\
2 & Dozer & 1 & 1 \\
3 & Dump Truck & 4 & 25 \\
\hline
\end{tabular}

(Hasil Perhitungan, 2018)

\section{SIMPULAN}

Pada akhir penyusunan tugas akhir ini, adapun kesimpulan antara lain :

1. Hasil produktivitas Excavator bedasarkan perhitungan didapat:

- Produksi per/jam $=60,00 \mathrm{~m}^{3} / \mathrm{jam}$ dan

- Excavator kebutuhan alatnya berjumlah 1 unit penggunaan dilapangan berjumlah 1 unit.

- Pengunaan alat sesuai dengan kebutuhan.

2. Hasil produktivitas Dump Truck bedasarkan perhitungan didapat:

- Produksi per/jam $=15,68 \mathrm{~m}^{3} / \mathrm{jam}$ dan

- Dump Truck kebutuhan alatnya berjumlah 4 unit penggunaan dilapangan berjumlah 25 unit.

- Jadi pengunaan Dump Truck di katakana boros.

3. Hasil produktivitas Dozer bedasarkan perhitungan didapat:

- Produksi per/jam $=52,47 \mathrm{~m}^{2} / \mathrm{jam}$

- Dozer kebutuhan alatnya berjumlah 1 unit penggunaan dilapangan berjumlah 1 unit.

- Penggunaan alat sesuai dengan kebutuhan.

\section{DAFTAR PUSTAKA}

Afandi, M. C. (2014). Perhitungan Produktifitas Alat Berat dalam Pekerjaan Longsoran pada Ruas Jalan Simpang Perdau-Batu Ampar sta 25+ 7501 Titik Kecamatan. Sangkulirang Kab. Kutai Timur. Kurva S Jurnal Mahasiswa, 4(1), 153-160.

Gafur, A. (2013). analisa perhitungan produktifitas alat berat pada pelaksanaan pematangan lahan untuk pembuatan work shop di kabupaten. Malinau pada dinas pekerjaan umum Provinsi Kalimantan timur. Kurva S jurnal mahasiswa, 1(1), 1-7.

Ilahi, R. R., Ibrahim, E., \& Swardi, F. R. (2014). Kajian Teknis Produktivitas Alat Gali-muat (Excavator) Dan Alat Angkut (Dump Truck) Pada Pengupasan Tanah Penutup Bulan September 2013 Di Pit 3 Banko Barat PT. Bukit Asam (Persero) Tbk Upte. Jurnal IImu Teknik, 2(3).

Pratasis, P. A. K. (2016). Kelayakan investasi studi kasus alat berat Buldozer, excavator dan dump truck di kota Manado. Jurnal Sipil Statik, 4(9).

Rajasa, A. C. C. Analisa penggunaan alat berat berdasarkan pada efisiensi pekerjaan galian pembangunan Jember Icon.

Rochmanhadi.1982 Alat - alat Berat dan Pengunaannya. Jakarta : Yayasan Badan Penerbit Pekerjaan Umum.

Rochmanhadi 1984. Perhitungan Biaya Pelaksanaan Pekerjaan Dengan Menggunakan Alat Berat. Jakarta : Yayasan Penerbit Pekerjaan Umum.

Suyono sosrodarsono. Perhitungan biaya pelaksanaan pekerjaan dengan mengunakan alat - alat berat, Dapartemen pekerjaan umum.
Rostiyanti Faneta Susy, 2008. Alat berat untuk proyek Kontruksi.jakarta, Penerbit: Rineka Cipta.

Tugas Akhir , 2014, Analisa Perhitungan Kebutuhan Alat Berat Pada Proyek Peningkatan Jalan Simpang Seling- Muaro Jernih Kabupaten Merangin,Afriadi. 